\title{
0 Pró-Saúde e 0 incentivo à inclusão de espaços diferenciados de aprendizagem nos cursos de odontologia no Brasil ${ }^{*}$
}

\author{
Marcos Alex Mendes da Silva ${ }^{1}$ \\ João Henrique Lara do Amaral² \\ Maria Inês Barreiros Senna ${ }^{3}$ \\ Efigênia Ferreira e Ferreira ${ }^{4}$
}

SILVA, M.A.M. et al. The National Reorientation of Vocational Healthcare Training (Pro-Saúde) and encouragement of inclusion of differentiated learning scenarios within dentistry courses in Brazil. Interface - Comunic., Saude, Educ., v.16, n.42, p.707-17, jul./set. 2012.

This study had the aim of ascertaining the situation regarding dentistry courses in Brazil that are involved in the National Reorientation of Vocational Healthcare Training (Pro-Saúde), in relation to different learning spaces. Document analysis was performed on the reports on the courses included in Pro-Saúde I. The item "teaching activity within the service network" and the timetabled workload of the course were the inclusion criteria. Out of 20 reports, 18 were included. There was diversity among the timetabled workloads of the higher education institutions for the primary care course, although all the institutions had students within this scenario. Five courses also included hospitals and specialized dentistry centers, and 11 included community projects. The incorporation of healthcare services as diversified learning scenarios varied, reflecting the different interpretations given regarding its importance, with consensus regarding the expectations generated by the Pro-Health stimulus.

Keywords: Pró-Saúde. Learning. Healthcare services. Community dentistry.
Este estudo objetivou conhecer a situação dos cursos de Odontologia no Brasil envolvidos com o Programa Nacional de Reorientação da Formação Profissional em Saúde - Pró-Saúde, em relação aos diferentes espaços de aprendizagem. Foi realizada análise documental dos relatórios dos cursos contemplados com o Pró-Saúde I. O item "atividade de ensino na rede de serviços" e a carga horária $(\mathrm{CH})$ de estágio foram os critérios de inclusão, e, dos vinte relatórios, 18 foram incluídos. Verificou-se uma diversidade entre as $\mathrm{CH}$ das Instituições de Ensino Superior (IES) destinadas ao estágio nos serviços da rede básica, embora todas apresentassem alunos neste cenário, cinco cursos incluíssem, ainda, os Hospitais/CEO (Centro de Especialidades Odontológicas), e 11 agregassem os projetos comunitários. A incorporação dos serviços de saúde como cenário diversificado de aprendizagem varia, refletindo as diferentes interpretações dadas a sua importância, com consenso na expectativa gerada pelo incentivo do Pró-Saúde.

Palavras-chave: Pró-Saúde. Aprendizagem. Serviços de saúde. Odontologia comunitária.

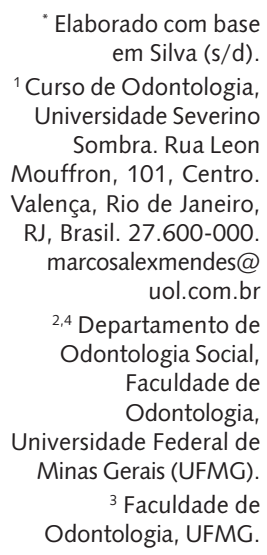

"Elaborado com base em Silva ( $\mathrm{s} / \mathrm{d}$ ).

${ }^{1}$ Curso de Odontologia, Universidade Severino Sombra. Rua Leon Mouffron, 101, Centro. Valença, Rio de Janeiro, RJ, Brasil. 27.600-000 marcosalexmendes@ uol.com.br

${ }^{2,4}$ Departamento de Odontologia Social, Faculdade de Odontologia Universidade Federal de Minas Gerais (UFMG). ${ }^{3}$ Faculdade de Odontologia, UFMG. 


\section{Introdução}

A preocupação mundial com a formação profissional na área de saúde abarca diferentes aspectos, que vão desde o conteúdo academicamente trabalhado em seu período de graduação, passando pelas estratégias pedagógicas utilizadas no processo formativo e nos espaços disponibilizados para a construção do conhecimento, até chegar à adequada valorização dos diferentes níveis de complexidade que compõem a atenção e a assistência à saúde. Quando o ensino supera a metodologia tradicional da transmissão vertical de conhecimentos, com maior ênfase no ensino do que na aprendizagem, voltando-se para a missão de atuar na produção de serviços, ganham destaque, na contextualização da integração ensino-serviço, estratégias pedagógicas inovadoras e a discussão de redes como espaços de conformação de um novo ator (Stella et al., 2009).

Nesse sentido, destacam-se as dimensões problematizadoras do processo ensino-aprendizagem, que assumem a construção do conhecimento como traço definidor da apropriação de informações e explicação da realidade, tomando-a como ponto de partida e chegada do processo de aprendizagem. A problematização se ancora no postulado de Paulo Freire que busca um sentido de inserção crítica na realidade para dela retirar os elementos que conferirão significado e direção à própria aprendizagem. Os conhecimentos são construídos a partir da rede de determinantes contextuais, das implicações pessoais e das interações entre os diferentes sujeitos que aprendem e ensinam (Batista et al., 2005).

Estudos apontam que os instrumentos pedagógicos adotados podem melhorar o processo de ensino-aprendizagem, possibilitando, aos estudantes, estarem mais preparados para enfrentar os desafios da vida profissional, como o desenvolvido por Hill-Sakura et al. (2008), professores do departamento de medicina da família e da comunidade da Universidade da Califórnia, nos Estados Unidos, sobre a abordagem do desenvolvimento profissional do currículo da escola médica. Este estudo foi realizado com alunos do terceiro ano, utilizando diferentes estratégias como ferramentas de aprendizagem, levando-os a destacarem os seguintes temas como os mais deficientes no seu processo de formação: (1) a transição para o estágio profissional de aprendizagem; (2) os desafios do comportamento profissional, e (3) os erros médicos. Com base no relato dos alunos envolvidos, o tema sobre comportamento profissional gerou 185 comentários, que se desdobravam: na dificuldade de comunicação entre profissional/paciente, no atendimento ao paciente movido pela compaixão, na responsabilidade e na pouca colaboração do trabalho em equipe. Concluíram que, uma instituição de ensino precisa adotar instrumentos de ensino-aprendizagem que valorizem o educando, como o trabalho com grupos focais e a adoção de relatórios críticos, que promovem o ensino reflexivo dos alunos, objetivando melhorar o posterior comportamento profissional.

Outro componente importante no processo ensino-aprendizagem constitui o ambiente em que ele se dá, o qual, quando motivador, contribui para determinar o sucesso acadêmico do aluno. Esse fato foi demonstrado em estudo realizado no Melaka Manipal Medical College (MMMC) (Manipal Campus Índia), por Abraham et al. (2008), ao compararem as percepções de estudantes de primeiro ano de medicina com as dos que se encontravam na fase clínica da formação, sobre o ambiente de aprendizagem. Embora os alunos do primeiro ano estivessem mais satisfeitos com o ambiente de aprendizagem no $M M M C$, em comparação com os estudantes dos períodos mais avançados, o estudo revelou áreas problemáticas no ambiente de aprendizagem da escola, a partir das quais foi possível adotar algumas medidas corretivas e vislumbrar a diversificação dos cenários de aprendizagem.

$\mathrm{Na}$ Faculdade de Medicina de Marília (Famema), os processos de formação dos profissionais de saúde vêm passando por transformações, com a implementação de um currículo integrado, utilizando, em sua metodologia de ensino, a diversificação de cenários de aprendizagem. Foi avaliada a percepção dos acadêmicos das duas primeiras séries iniciais acerca das ações em saúde que desenvolvem com a comunidade na Unidade Educacional de Prática Profissional (UPP), no cenário da Atenção Básica de Saúde (ABS). O estudo permitiu categorizar suas ações em quatro grandes temas no primeiro ano: a construção do conhecimento no cotidiano das ações de saúde; a contribuição social do estudante; o aprimoramento das relações e o olhar para as diversidades. No segundo ano, foram categorizados dois temas: a formação de um novo olhar sobre o SUS e a ampliação dos cuidados a partir de necessidades de saúde. Evidenciam-se, então, percepções comuns entre ambas as séries do curso em relação à 
aprendizagem na $A B S$, mostrando a importância que este cenário tem no processo ensino-aprendizagem, notadamente na construção de sujeitos críticos e reflexivos, capazes de aprender a aprender com a realidade na qual se inserem (Ferreira, Silva, Aguera, 2007).

O processo ensino-aprendizagem na área de saúde sofre, assim, influência direta dos instrumentos pedagógicos adotados em sua prática e das condições do ambiente onde estas práticas acontecem. $\mathrm{A}$ formação profissional distante da realidade do serviço de saúde e das demandas assistenciais reais esgotou um modelo pedagógico tradicional. Desse esgotamento, originaram-se medidas alternativas no processo de ensino, sobretudo com alusão ao aprendizado nas práticas extramurais.

Durante muitos anos, questionou-se a inadequação e a insuficiência do conteúdo disciplinar na formação na área de saúde, que não permitia aos acadêmicos estarem preparados para a abordagem da clientela em ambientes diferentes dos consultórios e próximos da realidade de trabalho necessária à sociedade. Nos últimos anos, os países membros da Organização Mundial de Saúde (OMS) têm enfatizado a necessidade de alinhar a prática e a formação profissional em saúde como ferramentas fundamentais para reverter este quadro.

A América Latina apresenta uma estrutura com extensos problemas de cunho social, epidemiológico e demográfico, que impõem, aos serviços de saúde, novos e crescentes desafios ou demandas, tendo como agravante, nesse panorama, uma formação profissional em geral fragmentada, centrada em aspectos biológicos, superespecializada, privilegiando o cenário clínico-curativo.

Dessa forma, impõe-se contemplar, na formação acadêmica, a dimensão psicossocial do processo saúde/doença, para que o futuro profissional de saúde tenha despertada a sua sensibilidade e a sua consciência para as questões de ordem subjetiva e coletiva presentes em seu cotidiano de trabalho, tornando-se um agente promotor da elevação da qualidade de vida da população, que é, em última instância, um dos objetivos amplos das políticas públicas e, portanto, da educação (Cabral et al., 2007).

Compreende-se a diversificação dos cenários de aprendizagem como uma das estratégias para a transformação curricular e aproximação dos estudantes com a vida cotidiana das pessoas, desenvolvendo olhares acadêmicos críticos e voltados para os problemas reais da população, ainda conforme os autores.

Ratificam, ainda, que os cenários de aprendizagem não devam se restringir aos locais de desenvolvimento de práticas profissionais, como espaços físicos de trabalho, mas, sim, representarem espaços em que as relações dos sujeitos sejam eficazmente desenvolvidas e possibilitem a incorporação do estudante ao processo de produção do serviço e gerem mudanças no processo de formação profissional.

[...] Uma das opções dessa diversificação é a aprendizagem baseada na comunidade, na qual o estudante permanece, durante sua formação, inserido num processo dinâmico de práticas integradas à comunidade, produzindo conhecimento e serviço de saúde para a população. Esse tipo de educação requer envolvimento dos educandos com a comunidade, fazendo-se reflexões acerca das práticas em saúde envolvidas para a construção de sua aprendizagem, diferentemente dos processos de formação que envolvem breves estágios em centros de saúde-escola. (Ferreira, Silva, Aguera, 2007, p.54)

Cabe uma reflexão sobre a compreensão conceitual e dialética em torno do trinômio ensino-serviçocomunidade, que aponta para a complexidade de sua triangulação, com o qual estudantes e docentes devem interagir. Primeiramente, há o estranhamento decorrente do confronto dos diferentes interesses postos em contato. Fazer confluírem pontos convergentes dos três universos distintos (docentes, acadêmicos e comunidade) é tarefa desafiadora, cujo roteiro de execução deve ser construído a partir de cada situação concreta, sem esquemas preconcebidos que possam prejudicar a percepção da realidade. Outras dificuldades apontadas referem-se, primeiramente, ao plano organizacional da interação, que congrega distintas instituições, com seus respectivos códigos, regimentos, finalidades e cultura institucional, nos quais as diferenças burocráticas e ideológicas podem desaguar em conflito, e na ausência de variáveis do fenômeno ensino-aprendizagem normativamente constituídas, pela incipiência dos processos de interação ensino-serviço e de indicadores apropriados que permitam o adequado monitoramente e avaliação (Cabral et al., 2007). 
Contudo, a opção por diversificar os cenários da aprendizagem foi incorporada por diferentes instituições de ensino em diversos lugares, como estratégia necessária na formação em saúde. A diversificação do processo de ensino-aprendizagem transpõe as fronteiras da sala de aula por meio de um modelo pedagógico que equilibra a excelência técnica e a relevância social, com métodos pedagógicos ativos, centrados nos alunos. Sugerem inserir a vivência prática, destinando parte da carga horária curricular às reflexões e atividades com/ e nos próprios serviços de saúde, com base na relação de parceria e integração da universidade com os mesmos, com a comunidade, com as entidades e com outros setores da sociedade civil (Ferreira, Cotta, Oliveira, 2009).

No campo da Odontologia, o processo de formação acadêmica passou por inúmeras transformações nas últimas três décadas, acompanhando as orientações advindas dos serviços de saúde, como produto da demanda assistencial da população. Somem-se a isso, as iniciativas ministeriais e os programas de fomento criados para possibilitarem a interação da academia com os serviços do SUS local, que mudaram os caminhos do ensino odontológico no Brasil.

A matéria-prima que definiu as demandas do sistema de saúde bucal foi o processo de avaliação em saúde, constituindo um processo crítico-reflexivo sobre as práticas e os processos desenvolvidos no âmbito dos serviços de saúde, de caráter contínuo e sistemático, que teve, em seu objeto - a atenção básica -, a complexidade e a abrangência que lhe são inerentes.

Pelo pressuposto, consiste em uma estratégia capaz de diagnosticar e apontar as dificuldades dos sistemas de saúde, sobretudo aquelas oriundas da formação dos profissionais que o integram, gerando, inúmeras vezes, uma rotatividade profissional no nível da atenção básica, resultando na carência de recursos humanos permanentes no SUS (Brasil, 2005).

A partir dos processos de avaliação e monitoramento dos sistemas de saúde, pôde-se perceber a carência de recursos humanos qualificados no setor, aliada à já referida dificuldade formativa, expressa, no campo da Odontologia, pelo profissional individualista, com uma prática predominantemente curativa, descompromissado com o contexto social no qual seus usuários estão cotidianamente inseridos.

As intensas críticas ao ensino da odontologia e ao sistema de saúde onde os profissionais egressos se instalavam, por volta dos anos 1980, apontaram a necessidade de se repensar a formação e, sobretudo, o destino do conhecimento produzido; e, embora não conseguissem gerar mudanças na forma de organização do ensino à época, impulsionaram o reordenamento curricular dos cursos de graduação de Odontologia nas décadas seguintes, sem contudo conseguir se libertar da primazia da produção intensiva dos artefatos odontológicos sofisticados (Garrafa, Moysés, 1996).

O ensino odontológico no Brasil carecia de transformações estruturais que modificassem o perfil de seus formandos e enfrentassem algumas dificuldades apontadas nesta afirmação, quando analisa a fragmentação do ensino na área de saúde:

[...] o dinamismo da totalidade da situação de adoecimento apresentada pelos pacientes ("a doença como objeto empírico") é artificialmente suspenso e por esse artifício lógico, a totalidade é cartesianamente decomposta (fragmentada), tem a sua integralidade negada (racionalmente), atomizada (intencionalmente) e isolada (didaticamente). [...] Assim o projeto pedagógico novecentista nas ciências da saúde foi instituído sem articulação íntima entre a teoria e a prática, entre disciplinas curriculares básicas e profissionalizantes. (Zanetti, 2006, p.22)

Zanetti (2006) afirma, ainda, que a proposta de integração curricular para os cursos de Odontologia deveria vir acompanhada de profunda interação entre teoria e prática e entre disciplinas básicas e profissionalizantes, para que o rearranjo curricular não configurasse apenas agrupamento de conteúdo, mas construção coletiva e democrática do conhecimento.

Na mesma medida da reestruturação da formação acadêmica da década de 1990, houve a necessidade de se proporem modelos assistenciais em saúde bucal, estruturados a partir do reordenamento da prática odontológica, com mudanças sensíveis na abordagem do processo saúde-doença, tendo o SUS como base filosófica e programática para essa necessária mudança conceitual (Oliveira et al., 1999). 
A almejada mudança dos centros formadores e dos serviços de saúde bucal da década de 1990 conduz à mobilização de várias instituições, no sentido de intensificar a aproximação das escolas de Odontologia com os serviços públicos de saúde, a partir dos quais as práticas orientariam e compartilhariam o aprendizado discente, melhorando, assim, os serviços prestados à comunidade, ainda segundo os autores.

As Diretrizes Curriculares Nacionais (DCN) para os cursos da área de saúde, estabelecidas em 2002, como resultado das novas conjunturas previstas pela Lei de Diretrizes e Bases da Educação n 9394/96 e pela Reforma Sanitária Brasileira, propunham uma flexibilização na organização dos currículos pelas IES e uma base comum para os referidos cursos, sinalizando a necessidade de maior interação ensino-serviçocomunidade. Superando o currículo mínimo hegemônico, as DCN conferem, às IES, liberdade para elaborarem seus projetos político-pedagógicos, segundo sua realidade, adequando-os às demandas sociais e aos avanços técnico-científicos (Brasil, 2002).

O documento abre espaço para o diálogo entre as áreas do conhecimento e destas com a sociedade, buscando a necessária interação da IES com o serviço de saúde, para juntas desenvolverem: a integralidade no cuidado à saúde e nas relações humanas, a valorização da autonomia, o trabalho em equipe e a aprendizagem contextualizada ao longo da vida.

Essa mudança paradigmática do currículo acadêmico tornou-se possível pelo incentivo do Ministério da Saúde, com projetos como o Programa de Incentivo a Mudanças Curriculares nos Cursos de Medicina - PROMED, e, mais recentemente, o Programa Nacional de Reorientação da Formação Profissional em Saúde - PRÓ-SAÚDE, que enfatizam a importância da integração da escola com os serviços de saúde, chamando a atenção para os locais de prática de ensino (Stella et al., 2009).

O Ministério da Saúde, por meio da Secretaria de Gestão do Trabalho e da Educação em Saúde (SGTES), elaborou, em conjunto com a Secretaria de Educação Superior (SESu) e com o Instituto Nacional de Estudos e Pesquisas Educacionais Anísio Teixeira (INEP) do Ministério da Educação, o Programa Nacional de Reorientação da Formação Profissional em Saúde - Pró-Saúde. A proposta levou em conta a sustentação estrutural indicada pelas Diretrizes Curriculares Nacionais e estabelecida pelo Conselho Nacional de Educação para as profissões de saúde, bem como o Sistema Nacional de Avaliação da Educação Superior (SINAES), possibilitando intervir nos cenários de prática do serviço público, tornando-os mais próximos da realidade dos futuros cirurgiões-dentistas, e mais atraentes à sua permanência (Brasil, 2007).

Os cursos de Odontologia foram contemplados por meio da Portaria Interministerial MS/MEC $\mathrm{n}^{\circ}$ 2.101, de 03 de novembro de 2005, com o Pró-Saúde, com a perspectiva de que os processos de reorientação acompanhassem simultaneamente distintos eixos, antevendo uma escola formadora integrada ao serviço público de saúde, fortalecendo, assim, a capacidade gestora e resolutiva do Sistema Único de Saúde (SUS) (Brasil, 2005a).

O documento (Brasil, 2007) oficial mostra que o objetivo geral do programa é a integração ensinoserviço, visando à reorientação da formação profissional, assegurando uma abordagem integral do processo saúde-doença com ênfase na atenção básica, promovendo transformações nos processos de geração de conhecimentos, ensino e aprendizagem e de prestação de serviços à população.

O objetivo central do Pró-saúde em apoiar as mudanças curriculares nos cursos de graduação da área de saúde, fazendo a necessária aproximação academia-serviço, traduz-se em práticas sanitárias mais adequadas às necessidades manifestas, refletindo, diretamente, em uma atenção à saúde de melhor qualidade (Haddad, Morita, 2006).

Dentre os eixos de trabalho propostos pelo programa, o eixo de cenários de prática aponta para a progressiva desinstitucionalização das práticas dos futuros profissionais de saúde (muitas práticas assistenciais poderão desenvolver-se em ambulatórios, na comunidade e nos domicílios), conforme Brasil (2007), contrapondo-se à tendência hegemônica realizada em ambientes sofisticados e de mais cara utilização. Os cenários em que se desenvolve o aprendizado prático durante a formação profissional, devem, portanto, ser diversificados, agregando-se ao processo, além dos equipamentos de saúde, equipamentos educacionais e comunitários.

Propõe, ainda, que a interação ativa do aluno com a população e com os profissionais de saúde deva ocorrer desde o início do processo de formação, proporcionando ao estudante trabalhar sobre problemas reais, e assumir responsabilidades crescentes, compatíveis com seu grau de autonomia. 
O objetivo desse estudo consistiu em conhecer a situação dos cursos de Odontologia no Brasil em relação à diversificação dos cenários de aprendizagem discente, acompanhando a proposta do Programa Nacional de Reorientação da Formação Profissional em Saúde - Pró-Saúde, em seu eixo de cenários de prática, por meio da análise da carga horária destinada à pratica de estágio dos alunos.

\section{Materiais e métodos}

Trata-se de um estudo transversal, descritivo e exploratório, que utilizou, como fontes de pesquisa, os relatórios do primeiro ano de execução do Pró-Saúde I, das diferentes instituições de ensino odontológico/secretarias municipais de saúde no Brasil.

A estratégia adotada para avaliação das informações contidas nos relatórios foi a análise documental, que consiste na organização do conteúdo pesquisado em fontes oficiais, porém não cientificamente trabalhadas (Victora, Knauth, Hassen, 2000), com possibilidade de complementaridade e aprofundamento de análise por meio da triangulação de métodos como a entrevista e os levantamentos survey.

A pesquisa com uso de documentos também necessita da elaboração de um questionamento inicial - o problema da pesquisa, que orientará a análise de suas informações. Desta forma, o pesquisador poderá fazer uma leitura hermenêutica, e não apenas literal da documentação, com uma compreensão real e contextualizada do que se intencionou estudar (Corsetti, 2006).

A análise documental passa pela etapa de localização das fontes e sua catalogação, criando arquivos individualizados, e sua organização significa processar a leitura segundo critérios da análise de conteúdo, comportando algumas técnicas, tais como: fichamento, levantamento quantitativo e qualitativo de termos e assuntos recorrentes, criação de códigos para facilitar o controle e manuseio, resultando em quadros, ou banco de dados de informações, que sintetizem todo conteúdo de interesse (Pimentel, 2001).

O processo de análise de conteúdo dos documentos tem início quando o pesquisador analisa: o contexto da elaboração do documento, as intenções do autor, a autenticidade, a confiabilidade e a natureza do texto, e, por fim, os conceitos-chave e sua lógica interna (Sá-Silva, Almeida, Guindane, 2009).

Contudo, será a decisão sobre a unidade de análise, pelo pesquisador, que definirá a forma de apropriação da informação: na unidade de registro importam os segmentos específicos do conteúdo, determinando, por exemplo, a frequência com que aparece, no texto, uma palavra, um tema, ou um determinado item (neste estudo, o item relativo à atividade de ensino na rede de serviços e sua correspondente carga horária semestral); enquanto que, para unidade de contexto, pode ser mais importante explorar o contexto em que um determinado fenômeno ocorre, e não apenas sua frequência, ainda segundo os autores.

Neste estudo optou-se pela análise a partir da unidade de registro, cuja apresentação dos dados, na forma de uma tabela de distribuição de frequência, foi capaz de demonstrar a situação da aprendizagem em cenários diferenciados de prática por meio de suas cargas horárias semestrais, considerando as três categorias de análise avaliadas: carga horária de estágio em Hospitais/CEO, em USF/UBS e em projetos comunitários.

Inicialmente, foram incluídos vinte relatórios de um universo de 25 cursos de Odontologia contemplados com o Pró-Saúde I, por estarem publicamente disponíveis no site oficial do Programa Pró-Saúde, mantido pela Secretaria de Gestão do Trabalho e da Educação em Saúde (SGTES) do Ministério da Saúde. Deste total, foram excluídos dois relatórios que não contemplavam o item "atividade de ensino na rede de serviços" e nem faziam menção à distribuição de alunos em cenários diferenciados de aprendizagem.

A partir do item escolhido como critério de inclusão no estudo, foram analisados 18 relatórios oficiais, para o qual se construiu uma tabela com as cargas horárias de aprendizagem em espaços diferentes das clínicas da IES e das salas de aula, o que permitiu delinear a situação de diversificação dos cenários de aprendizagem adotados pelos referidos cursos de Odontologia, tendo sido preservado o anonimato das IES, garantindo, assim, a privacidade das informações. 


\section{Resultados e discussão}

A análise documental dos relatórios permitiu construir a Tabela 1, na qual as instituições de Ensino Superior são avaliadas segundo os cenários diversificados de aprendizagem adotados pelos respectivos períodos acadêmicos, com a correspondente carga horária. Foram desconsideradas as clínicas dos próprios cursos e as salas de aula, por se entender que estes cenários compõem os espaços tradicionalmente usados no ensino odontológico.

Tabela 1. Distribuição das IES segundo os períodos acadêmicos e a carga horária destinada aos cenários diversificados de aprendizagem

\begin{tabular}{|c|c|c|c|c|}
\hline \multirow[b]{3}{*}{ IES } & \multicolumn{4}{|c|}{$\begin{array}{l}\text { Cenários diversificados de aprendizagem } \\
\text { (Períodos acadêmicos/cenários/carga horária por aluno) }\end{array}$} \\
\hline & \multirow[b]{2}{*}{ Períodos } & \multicolumn{3}{|c|}{ Carga horária } \\
\hline & & Hospitais e CEO & ESF (USF/UBS) & Projetos Comunitários \\
\hline IES 1 & todos & 160 & 72 & 72 \\
\hline IES 2 & 1 e 2 & & 70 & \\
\hline IES 3 & 7 & & 30 & \\
\hline IES 4 & $4,5,8$ e 9 & 72 & 72 & \\
\hline IES 5 & todos & & 34 & 119 \\
\hline IES 6 & 1,2 e $5-10$ & & 63,5 & 48 \\
\hline IES 7 & 2,3 e 8 & 72 & 72 & 72 \\
\hline IES 8 & 2 e 6 & & 24 & 70 \\
\hline IES 9 & 2,3 e $7-10$ & & 178 & 8 \\
\hline IES 10 & 2 e 9 & & 363 & \\
\hline IES 11 & 5,7 e 9 & & 60 & 80 \\
\hline IES 12 & $6-8$ & & 60 & \\
\hline IES 13 & Todos & 450 & 147 & 90 \\
\hline IES 14 & 4,5 e 7 & & 190 & \\
\hline IES 15 & 7 e 10 & & 720 & \\
\hline IES 16 & 1e $7-9$ & 6 & 94 & 50 \\
\hline IES 17 & $1-8$ & & 180 & 30 \\
\hline IES 18 & $5-8$ & & 216 & 162 \\
\hline
\end{tabular}

Observa-se uma variação de cenários adotados, com cursos de Odontologia que inserem seus alunos somente em cenários próprios da Atenção Básica e outros que ainda os inserem nos módulos de referência do sistema local de saúde, como o Centro de Especialidades Odontológicas e as unidades hospitalares. E ainda, dentro do mesmo cenário, cargas horárias que variam de quatro a setecentas e vinte horas semestrais de prática em serviços de UBS e/ou ESF (Mean $=76,81 \pm 96,54)(95 \% \mathrm{CI}$ 44,14-109,47).

Embora as médias de horas, nos cenários diversificados de aprendizagem dos alunos matriculados nos cursos de Odontologia contemplados com o Pró-Saúde I, apontem forte inserção dos alunos nas ESF/UBS e em projetos comunitários (64,5\% da carga horária total), remanescem, ainda, duas instituições (IES 1 e 13) nas quais seus alunos ainda passam mais tempo em Centros de Especialidades e Hospitais ( $52,6 \%$ do total de horas semestrais na IES 1 e $65,5 \%$ do total de horas semestrais na IES 13) do que em módulos de Atenção Primária e comunidades (47,4\% na IES 1 e $34,5 \%$ na IES 13).

Esta diferença em apenas dois dos 18 relatórios analisados remete às diferentes interpretações dadas à diversificação de cenários de aprendizagem, sobretudo aqueles apontados pelas $\mathrm{DCN}$ e reafirmados pelo Pró-Saúde, que, juntos, buscam uma formação profissional mais contextualizada com as 
necessidades da sociedade e inserida nos locais onde elas despontam. Esse remanescente dos espaços da atenção especializada na formação, no nível de graduação, em momento de reversão do modelo pelo incentivo do programa, leva, ainda, à suposição da predominância de uma visão hospitalocêntrica na resolução dos problemas de saúde nestas instituições de ensino, contrária às DCN e ao Pró-Saúde.

A flexibilidade curricular, trazida com as DCN, permite que cada instituição defina a carga horária mais apropriada às suas necessidades pedagógicas, modificando, assim, o tempo de permanência do aluno em contato com a rede de serviços local, embora todos os cursos se esforcem para atingir os 20\% mínimos exigidos de sua carga horária total.

Além da reflexão sobre o cenário adotado para a aprendizagem, surge, ainda, a reflexão sobre as diferentes cargas horárias nos próprios cenários da Atenção Primária à Saúde, no sentido de se entender como 24 horas semestrais definidas por uma instituição (IES 8) proporcionam o mesmo aprendizado que setecentas e vinte horas (IES 15), ambas distribuídas em dois períodos acadêmicos.

A partir daí, qual a carga horária mínima necessária de uso de cenários diferenciados de aprendizagem para se promover a desejada mudança formadora, considerando, ainda, os fatores locorregionais? E em que medida estão os cursos fazendo seu dever de casa, promovendo sua transformação gradual?

A análise deste relatório inicial pode, muito bem, estar dimensionando o período de transição pelo qual as instituições estavam passando, e, em estágios diferentes, estarem cada uma buscando transpor seus limites necessários à adequação metodológica, saindo da lógica curativa e caminhando para o promocional.

As instituições, nas quais a mudança segue mais vagarosamente, enfrentam algumas dificuldades, e, em alguns relatos, sobressaem as arestas da relação entre a academia e os serviços de saúde, que, se não se comunicavam, precisaram dialogar e estabelecer parcerias, com responsabilidades definidas. E como estabelecer consenso entre instituições com diferentes interesses e múltiplos atores, convergindo para um mesmo objetivo?

Está posto o grande desafio, onde o relato de experiência de uma IES - na qual a Secretaria Municipal de Saúde local recusou-se a assumir responsabilidades na inserção dos alunos na rede pública de serviços - levou a instituição de ensino a buscar ajuda em um município vizinho, e somente diante deste aceite, o primeiro município recuou e absorveu a demanda inicialmente apontada.

Diante das dificuldades enfrentadas na obtenção do consenso no poder decisório, as instituições IES e SMS - depositam suas expectativas na capacidade do Pró-Saúde de equacionar os problemas, sem se darem conta de que o programa traz as diretrizes, mas as ações foram planejadas pelos próprios atores, e sua execução dependerá exclusivamente dos mesmos. Os conflitos que surgem durante o desenvolvimento das ações programadas não poderiam ser minimizados, se tivessem sido previstos no período do planejamento conjunto?

\section{Considerações finais}

Em maior ou menor grau, todas as escolas avaliadas demonstraram adotar os espaços do SUS local como cenários diversificados de aprendizagem, embora com diferentes cargas horárias, fruto da concepção que cada unidade de ensino tem da importância de se diversificarem estes cenários, e para onde diversificar.

Definir uma carga horária mínima a ser dedicada ao contato do aluno com a Atenção Primária à Saúde ao longo de sua formação, as DCN já o fizeram, restando às instituições de ensino entenderem onde os problemas básicos de saúde bucal prevalecem, e lá inserirem seus alunos com a disponibilidade necessária para a real aprendizagem em serviço - aprendendo a aprender no chamado "mundo do trabalho". Não basta que todas as disciplinas convirjam para os cenários da Atenção Primária com microcargas horárias, mas, sim, devido a toda complexidade que o trabalho neste nível requer, é necessário que o aprendizado estruture-se para acontecer na própria realidade local.

O primeiro ano de mudança fomentado pelo Pró-Saúde corresponde ao desatar os nós de uma amarra feita há muito tempo, que privilegiava a formação do cirurgião-dentista voltado exclusivamente 
para a técnica; e, desta forma, exigirá tempo e esforço, cujos resultados começarão a aparecer à medida que o novo modelo de formação proposto começar a se consolidar, cabendo uma nova avaliação dos relatórios do Pró-Saúde no seu terceiro e último ano de execução da presente carta acordo.

Esta análise preliminar mostra a disposição dos cursos em formarem melhor seus graduandos, preparando-os para, de fato, responderem às demandas da população; carecendo, ainda, avançar na diversificação dos cenários de prática centrados nos cuidados primários de saúde, distanciando-se da prática mutiladora do ambiente hospitalar, e, na escala de complexidade da atenção à saúde, diminuir as necessidades secundárias e terciárias pela resolução dos problemas primários.

Projeta-se uma imagem-objetivo de que, no futuro, essas escolas analisadas distribuirão melhor seus tempos de aula nas unidades de saúde da família, na comunidade, nos domicílios, reafirmando um conceito tradicional de que a Odontologia é um curso prático, mas não no sentido da técnica somente, mas da vivência da realidade baseada em evidências.

O maior consenso a que se chega pela análise dos relatórios é a expectativa, gerada pela criação do Programa Pró-Saúde, no fortalecimento do ideário pensado pelos docentes, e aceito pelos gestores municipais de saúde, de se ter um ambiente de saúde de qualidade, com profissionais aprendendo e sendo formados para a resolutividade e para a efetividade do sistema.

\section{Colaboradores}

Os autores trabalharam juntos em todas as etapas de produção do manuscrito.

\section{Referências}

ABRAHAM, R., et al. Students' perceptions of learning environment in an Indian medical school. BMC Med. Educ., v.8, n.20, p.1-5, 2008.

BATISTA, N. et al. O enfoque problematizador na formação de profissionais da saúde. Rev. Saude Publica, v.39, n.2, p.231-7, 2005.

BRASIL. Ministério da Saúde. Ministério da Educação. Programa Nacional de Reorientação da Formação Profissional em Saúde - Pró-Saúde: objetivos, implementação e desenvolvimento potencial/Ministério da Saúde, Ministério da Educação. Brasília: Ministério da Saúde, 2007. (Série C, Projetos, Programas e Relatórios).

. Ministério da Saúde. Secretaria de Atenção à Saúde. Departamento de Atenção Básica. Coordenação de Acompanhamento e Avaliação na Atenção Básica em Saúde: caminhos da institucionalização. Coordenação técnica: Instituto de Saúde Coletiva da Universidade Federal da Bahia e Instituto Materno Infantil Prof. Fernando Figueira. Brasília: Ministério da Saúde, 2005.

Ministério da Saúde. Ministério da Educação. Portaria Interministerial n 2.101 de 3 de novembro de 2005a. Programa Nacional de Reorientação da Formação Profissional em Saúde - Pró-Saúde. Disponível em: <http://www.abemeducmed.org.br/publicacoes/boletim_virtual/volume_10/portaria_pro_saude.pdf $>$. Acesso em: 9 dez. 2009.

Ministério da Educação. Diretrizes Curriculares Nacionais dos Cursos de Graduação em Farmácia e Odontologia. CNE/CES nº 2, de 19 de fevereiro de 2002. Disponível em: <http://portal.mec.gov.br/cne/arquivos/pdf/CES1300.pdf>. Acesso em: 10 fev. 2010.

CABRAL, P.E. et al. Serviço e comunidade, vetores para a formação em saúde: o curso de medicina da Uniderp. Rev. Bras. Educ. Med., v.32 n.3, p.374-82, 2008. 
CORSETTI, B. A análise documental no contexto da metodologia qualitativa: uma abordagem a partir da experiência de pesquisa do Programa de Pós-Graduação em Educação da Unisinos. UNIrevista, v.1, n.1, p.32-46, 2006.

FERREIRA, M.L.S.M.; COTTA, R.M.M.; OLIVEIRA, M.S. Construção coletiva de experiências inovadoras no processo ensino-aprendizagem na formação de profissionais da saúde. Rev. Bras. Educ. Med., v.33, n.2, p.240-6, 2009.

FERREIRA, R.C.; SILVA, R.F.; AGUERA, C.B. Formação do profissional médico: a aprendizagem na Atenção Básica de Saúde. Rev. Bras. Educ. Med., v.52, n.1, p.52-9, 2007.

GARRAFA, V.; MOYSÉS, S.L. Odontologia brasileira: tecnicamente elogiável, cientificamente discutível, socialmente caótica. Divulg. Saude Debate, v.13, n.13, p.6-17, 1996.

HADDAD, A.E.; MORITA, M.C. O ensino da Odontologia e as políticas de saúde e de educação. In: CARVALHO, A.C.P.; KRIGER, L. (Orgs.). Educação odontológica. São Paulo: Artes Médicas, 2006. v.1, p.105-17.

HILL-SAKURA, L.E. et al. A professional development course for the clinical clerkships: developing a student-centered curriculum. J. Gen. Intern. Med., v.23, n.7, p.964-8, 2008.

OLIVEIRA, A.G.R.C. et al. Modelos assistenciais em saúde bucal no Brasil: tendências e perspectivas. Ação Colet., v.2, n.1, p.9-14, 1999.

PIMENTEL, A. O método da análise documental: seu uso numa pesquisa historiográfica. Cad. Pesqui., n. 114, p. 179-95, 2001. Disponível em: <http://www.scielo.br/pdf/cp/n114/a08n114.pdf>. Acesso em: 18 abr. 2010.

SÁ-SILVA, J.R.; ALMEIDA, C.D.; GUINDANE, J.F. Pesquisa documental: pistas teóricas e metodológicas. Rev. Bras. Hist. Cienc. Soc., v.1, n.1, p.1-15, 2009.

SILVA, M.A.M. A diversificação dos cenários de aprendizagem na formação do profissional de Odontologia. s/d. Tese (Doutorado em andamento) - Programa de Pósgraduação em Odontologia, Faculdade de Odontologia, Universidade Federal de Minas Gerais, Belo Horizonte. s/d.

STELLA, R.C.R. et al. Cenários de prática e a formação médica na assistência em saúde. Rev. Bras. Educ. Med., v.33, supl.1, p.63-9, 2009.

VICTORA, C.G.; KNAUTH, D.R.; HASSEN, M.N.A. Pesquisa qualitativa em saúde: uma introdução ao tema. Porto Alegre: Tomo Editorial, 2000. p.59-78.

ZANETTI, C. A formação do cirurgião-dentista. In: ANGELIM DIAS, A. (Org.). Saúde bucal coletiva. São Paulo: Santos, 2006. p.21-42. 
SILVA, M.A.M. et al. El Pro-Salud y El fomento de la inclusión de diferentes áreas de aprendizaje em los cursos de odontología en Brasil. Interface - Comunic., Saude, Educ., v.16, n.42, p.707-17, jul./set. 2012.

El objetivo de este estudio es el de conocer la situación de los cursos de odontología en Brasil relacionados al Programa Nacional de Re-orientación de la Formación Profesional en Salud, Pro-Salud, en relación a los diferentes espacios de aprendizaje. Se ha realizado un análisis documental de los informes de los cursos contemplados en el Pro-Salud I. La "actividad de enseñanza en la red de servicios" y la "carga horaria" $(\mathrm{CH})$ correspondiente han sido los criterios de inclusión; de los 20 informes, 18 fueron incluidos. Se verificó una diversidad entre las $\mathrm{CH}$ de las Instituciones de la Enseñanza Superior (IES) destinadas al período de práctica en los servicios de la red básica; aunque todas presentasen alumnos en este cuadro, cinco cursos incluyesen también los hospitales del Centro de Especialidades Odontológicas (CEO) i 11 agregasen los proyectos comunitarios. La incorporación de los servicios de salud reflejando las diferentes interpretaciones dadas a su importancia como consenso en la expectativa por el fomento del Pro-Salud.

Palabras-clave: Pro-Salud. Aprendizaje. Servicios de salud. Odontología comunitaria. 